\title{
No evidence for point mutations in the novel renal cystine transporter AGT1/ SLC7A13 contributing to the etiology of cystinuria
}

\author{
Kathrin Olschok ${ }^{1}$, Udo Vester ${ }^{2}$, Sven Lahme ${ }^{3}$ Ingo Kurth ${ }^{1}$ and Thomas Eggermann ${ }^{1 *}$
}

\begin{abstract}
Background: Cystinuria is caused by the defective renal reabsorption of cystine and dibasic amino acids, and results in cystine stone formation. So far, mutations in two genes have been identified as causative. The SLCBA1/rBAT gene encodes the heavy subunit of the heterodimeric rBAT- $b^{0,+} A T$ transporter, whereas the light chain is encoded by the SLC7A9/ $b^{0,+} A T$ gene. In nearly $85 \%$ of patients mutations in both genes are detectable, but a significant number of patients currently remains without a molecular diagnosis. Thus, the existence of a further cystinuria gene had been suggested, and the recently identified AGT1/SLC7A13 represents the long-postulated partner of rBAT and third cystinuria candidate gene.

Methods: We screened a cohort of 17 cystinuria patients for SLC7A13 variants which were negative for SLC3A1 and SLC7A9 mutations.

Results: Despite strong evidences for an involvement of SLC7A13 mutations in cystinuria, we could not confirm a relevant role of SLC7A13 for the disease.

Conclusion: With the exclusion of SLC7A13/AGT1 as the third cystinuria gene accounting for the SLC3A1 and SLC7A9 mutation negative cases, it becomes obvious that other genetic factors should be responsible for the cystinuria phenotype in nearly $15 \%$ of patients.
\end{abstract}

Keywords: Cystinuria, Mutation, AGT1/SLC7A13

\section{Background}

Cystinuria (OMIM 220100) is a congenital disorder characterized by the defective renal reabsorption of cystine and other dibasic amino acids in the proximal renal tubule and in the epithelial cells of the gastrointestinal tract (for review: [1]). The resulting hyperexcretion of cystine leads to its precipitation in the distal tubule and formation of cystine stones. In adults cystine stones account for only $1-2 \%$ of all nephrolithiasis patients, whereas cystine stones account for $6-8 \%$ of pediatric urolithiasis patients [2].

\footnotetext{
* Correspondence: teggermann@ukaachen.de

${ }^{1}$ Institute of Human Genetics, University Hospital, Technical University RWTH

Aachen, Pauwelsstr. 30, D-52074 Aachen, Germany

Full list of author information is available at the end of the article
}

So far, two autosomal genes have been identified to harbor genetic variants causing cystinuria. The SLC3A1/ $r B A T$ gene in $2 \mathrm{p} 21$ encodes the heavy subunit of the heterodimeric $r B A T-b^{0,+} A T$ transporter, the light chain is encoded by the SLC7A9/ $b^{0,+} A T$ gene in $19 \mathrm{q} 12$ [3-7]. The transporter is localized in the apical membrane of proximal tubules in the kidney and mediates the reabsorption of cystine, arginine, ornithine and lysine. Genomic variants in both genes have been identified in cystinuria patients. Whereas mutations in SLC3A1 are commonly inherited in an autosomal recessive manner, SLC7A9 alterations show a broad variability of inheritance, ranging from autosomal recessive to dominant. In some patients large genomic deletions in 2p21 affecting the $S L C 3 A 1$ gene and its neighbored PREPL gene can be detected, in that case urolithiasis is associated with

(c) The Author(s). 2018 Open Access This article is distributed under the terms of the Creative Commons Attribution 4.0 International License (http://creativecommons.org/licenses/by/4.0/), which permits unrestricted use, distribution, and reproduction in any medium, provided you give appropriate credit to the original author(s) and the source, provide a link to the Creative Commons license, and indicate if changes were made. The Creative Commons Public Domain Dedication waiver (http://creativecommons.org/publicdomain/zero/1.0/) applies to the data made available in this article, unless otherwise stated. 
hypotonia and further clinical symptoms (HypotoniaCystinuria syndrome - HCS, OMIM 606407).

Comprehensive mutation analyses in both genes allow the detection of genetic variants in more than $85 \%$ of patients, but a significant number of patients currently remain without a molecular diagnosis. In fact, the lack to detect pathogenic mutations can be explained by the applied methods and their different sensitivities, the influence of the ethnic origin on the distribution of mutations, and the autosomal dominant impact of some mutations in SLC7A9 (and SLC3A1). However, they do not explain that a significant number of patients remains without any detectable mutation.

This observation as well as results of expression studies in the proximal renal tubule for rBAT and $b^{0,+} \mathrm{AT}$ indicated that further subunits of the plasma membrane protein $\mathrm{rBAT}$ are involved in the renal cystine reabsorption. In particular, the opposing expression of rBAT and $\mathrm{b}^{0,+} \mathrm{AT}$ with a decline of rBAT expression from S3 towards the S1 segment and vice versa points to the existence of a further factor. With AGT1 as the second partner of rBAT in the S3 segment, the long-postulated partner of rBAT in the S3 segment of the renal proximal tubule cystine transport has recently been identified [8].

Consequently, AGT1/ SLC7A13 has been suggested as a further candidate gene for cystinuria, mutations in this factor might explain the so far unsolved cases of cystinuria in which mutations in SC3A1 and SLC7A9 had been excluded. We here report on the results of our search for pathogenic genetic variants in SLC7A13 in a cohort of 17 patients without disease-causing variations in the known cystinuria genes.

\section{Methods}

In total, 103 patients from Germany, Turkey, Greece, Italy and Eastern Europe had been ascertained in precedent studies [9-15] aiming on the identification of SLC3A1 and SLC7A9 variants or in the course of routine molecular diagnostics of cystinuria because of (recurrent) nephrolithiasis or cystinuria. The study had been approved by the ethical committee of the Medical Faculty at the University Hospital Aachen (RWTH Aachen, EK302-16), Germany.

Analyses for disease-causing variants in SLC3A1 and SLC7A9 comprised Sanger sequencing analysis of their coding regions and the intron-exon boundaries (NM 000341.3, NM_014270.4), and search for whole exon deletions and duplications by multiplex ligation probedependent amplification (MLPA; kit P426-A1, mrc Holland, Amsterdam/NL).

The coding exons and the neighboring intron regions of SCL7A13 (NM_138817.2) were analyzed by Sanger sequencing after PCR amplification. Primers are listed in Table 1, PCR as well as sequencing conditions are available on request.

\section{Results}

In 103 cystinuria patients, $83.5 \%$ had at least one SLC3A1 or SLC7A9 mutation (Table 2). In $49.5 \%(n=$ 51) of patients, two mutations could be observed, either as homozygosity / compound heterozygosity in one of the two genes or as mixed heterozygosity in both genes. In $17.5 \%(n=18)$, one mutation was detected for which a penetrance in heterozygous state can be expected, i.e. the duplication of exons 5 to 9 in SLC3A1 or SLC7A9 mutations. In $16.5 \%(n=17)$, only one mutation in SLC3A1 was identified which would not explain the phenotype, in these cases a second mutation can be expected but is still undetected. In two patients we identified homozygosity / compound heterozygosity for large 2 p21 deletions, these patients were molecularly diagnosed as HCS as both SLC3A1 and PREPL were affected.

Mutation analysis for the two genes was negative in $16.5 \%$ of patients, and these 17 individuals (Table 3) were screened for pathogenic mutations in the coding sequences and the intron-exon boundaries of SLC7A13. However, with the exception of already known apathogenic polymorphisms (rs7814198, rs4419794, rs4621787, rs4546639, rs202114931, rs56993779, rs9656982) we did not detect any pathogenic genetic variant.

\section{Discussion}

In contrast to the majority of kidney stones which occur sporadically, cystine stone formation and cystinuria have been suggested to be exclusively caused by genomic mutations. This assumption was supported by the identification of mutations in cystinuria patients in the genes coding the two subunits of the renal rBAT- $\mathrm{b}^{0,+} \mathrm{AT}$ transporter. However, with the exception of populations with founder mutations (e.g. [16]), the detection rate for

Table 1 Primers used for Sanger sequencing of the coding sequences and exon-intron boundaries of the SLC7A13 gene

\begin{tabular}{llll}
\hline Exon & Foward Primer & Reverse Primer & Length of PCR product \\
\hline 1 & SLC7A13_1.1F: CTTTGCAGCTACATAGGCAGG & SLC7A13_1.1R: TAGGCAGCTTTGGGACAGAG & 471 \\
& SLC7A13_1.2F: TGGACATCCTGTTTCTGGGG & SLC7A13_1.2R: GGCTGGCATGATCTGATTCAG & 537 \\
3 & SLC7A13_2F: TAAAATCATGCTTGTACCCC & SLC7A13_2R: AACAGTGGTTCTGACTGGTG & 330 \\
4 & SLC7A13_3F: TCATTAGTATTTCTCTTTAACAC & SLC7A13_3R: TGTGTTTCACAGTAACTGAG & 541 \\
\end{tabular}


Table 2 Summary of the mutation detection results for SLC3A1 and SLC7A9 in a cohort of 103 cystinuria patients

\begin{tabular}{lllll}
\hline & two mutations & $\begin{array}{l}\text { one mutation } \\
\text { explaining } \\
\text { cystinuria }\end{array}$ & $\begin{array}{l}\text { only one } \\
\text { mutation }\end{array}$ & no mutation \\
\hline SLC3A1 & $39^{\circ}$ & 2 & 17 & $/$ \\
SLC7A9 & 11 & 16 & $/$ & $/$ \\
mixed & 1 & $/$ & $/$ & $/$ \\
total & $51(49.5 \%)$ & $18(17.5 \%)$ & $17(16.5 \%)$ & $17(16.5 \%)$
\end{tabular}

aheterozygosity of the duplication of exons 5 to 9 in SLC3A1 and of SLC7A9 mutations without parallel occurrence of a second mutation has been reported to be sufficient to cause cystinuria; ${ }^{\circ}$ including large HCS deletions

mutations in the SLC3A1 and SLC7A9 genes never reaches $100 \%$, and genetic variants in both genes account for $80-85 \%$ in the cystinuria population. This incomplete detection rate is certainly caused by methodological restrictions as non-coding regions (introns, promotor region) of the genes are commonly not investigated and the applied methods show different sensitivities. Furthermore, the penetrance of some mutations in both genes differs from the classical modes of Mendelian inheritance. In case of SLC3A1, mutations are generally autosomal recessively inherited, but at least the duplication of exons 5 to 9 in this gene has been suggested to function as an autosomal dominant allele [17]. For SLC7A9 the situation is more complex, in this gene

Table 3 Ovenview on the 17 patients screened for SLC7A13 mutations

\begin{tabular}{llllll}
\hline patient & $\begin{array}{l}\text { ethnic } \\
\text { origin }\end{array}$ & $\begin{array}{l}\text { age at first } \\
\text { stone }\end{array}$ & $\begin{array}{l}\text { age at } \\
\text { examination }\end{array}$ & $\begin{array}{l}\text { number of } \\
\text { recurrent } \\
\text { stones }\end{array}$ & published in \\
\hline Cys3 & Italian & $4 \mathrm{~m}$ & $12 \mathrm{y}$ & $5-10$ & {$[9]$} \\
Cys4 & Italian & $1 \mathrm{y}$ & $5 \mathrm{y}$ & $<5$ & {$[9]$} \\
Cys21 & Italian & - & $23 \mathrm{y}$ & none & {$[9]$} \\
Cys23 & Turkish & NA & $30 \mathrm{y}$ & $<5$ & {$[10]$} \\
Cys43 & German $19 \mathrm{y}$ & $51 \mathrm{y}$ & $>10$ & {$[10]$} \\
Cys58 & Turkish $6 \mathrm{y}$ & $16 \mathrm{y}$ & $<5$ & {$[14]$} \\
Cys63 & German $13 \mathrm{~m}$ & $3 \mathrm{y}$ & $5-10$ & {$[14]$} \\
Cys89 & Russian $25 \mathrm{y}$ & $30 \mathrm{y}$ & $<5$ & {$[14]$} \\
Cys98 & German $3.5 \mathrm{y}$ & $5 \mathrm{y}$ & $<5$ & {$[14]$} \\
Cys105 & Russian $1.5 \mathrm{y}$ & $12 \mathrm{y}$ & $5-10$ & {$[14]$} \\
Cys116 & Turkish $1.5 \mathrm{y}$ & $11 \mathrm{y}$ & $5-10$ & {$[12]$} \\
Cys128 & Turkish $17 \mathrm{y}$ & $23 \mathrm{y}$ & $>10$ & {$[12]$} \\
Cys152 & German NA & $\mathrm{NA}$ & $\mathrm{NA}$ & {$[12]$} \\
Cys161 & Turkish $1 \mathrm{~m}$ & $1 \mathrm{~m}$ & 1 & {$[12]$} \\
Cys181 & Polish $3 \mathrm{y}$ & $9 \mathrm{y}$ & $>10$ & {$[13]$} \\
Cys183 & Polish $6 \mathrm{y}$ & $6 \mathrm{y}$ & $5-10$ & {$[13]$} \\
M20679 & German NA & $52 \mathrm{y}$ & 1 & - \\
\hline
\end{tabular}

Mutations in the SLC3A1 and SLC7A9 genes had been excluded before (see texts). The majority of patients was in included in precedent studies. (NA not assessed; $y$ year, $m$ months) mutations can have both recessive as well as dominant effects. Thus, an autosomal dominant inheritance with incomplete penetrance has been suggested for variants in SLC7A9. In summary, the uncertainties to classify mutations in the already known cystinuria genes make the decision on the final detection rate difficult. Furthermore, it can be asked whether the detection of only one mutated allele in SLC3A1 or SLC7A9 is indeed sufficient to explain the cystinuria phenotype, or whether a second genomic variant in the same or another gene is required.

In addition to this unclear situation in patients with only one disease-causing mutation, there remains a considerable ratio of patients without a mutation in both genes. This observation provides strong evidence for the existence of a further factor mutations in which might cause cystinuria, but precedent mutation detection analyses in different candidate genes did not provide evidence for their involvement in the etiology of the disease (e.g. SLC1A5/ ATB(0), SLC7A10/ASC-1) [14, 18-21]. The recently described novel cystine transporter SLC7A13/AGT1 in the renal proximal tubule was a promising candidate to harbor pathogenic mutations in cystinuria patients. In particular, the observation that AGT1 serves as the second partner of the rBAT transporter in the S3 segment and its expression is consistent with the inversed expression of the so far known cystine transporter subunits $S L C 3 A 1 / \mathrm{rBAT}$ and $S L C 7 A 9 / \mathrm{b}^{0,+} \mathrm{AT}$ [8] strongly points to $S L C 7 A 13$ as a candidate gene for cystinuria.

Despite these strong evidences, we could not confirm a relevant role of $S L C 7 A 13$ as a third gene contributing to the pathology of cystinuria. In our cohort which was comprehensively analysed for SLC3A1 and SLC7A9 variants, we could not detect any pathogenic mutation in the coding sequences and intron-exon boundaries of SLC7A13. In fact, we cannot exclude large deletions or duplications affecting whole exons, or variants in the non-coding regions of the gene. However, these types of mutations generally contribute only to a small proportion of the mutation spectrum of inherited diseases.

With the exclusion of SLC7A13/AGT1 as the third cystinuria gene, the question remains unanswered why analysis for the two cystinuria genes SLC3A1 and $S L C 7 A 9$ succeeds only in up to $85 \%$. In fact, this finding can be explained by ethnic differences in the distribution of mutations, and by methodological limitations. However, the comprehensive analysis for SLC3A1 and SLC7A9 mutations in a large number of studies (for review see: $[1,22])$ does not indicate that a considerable number of genomic mutations in SLC3A1 or SLC7A9 has been missed. We therefore postulate that there is another genomic factor causing cystinuria. This factor might either been another so far unknown renal cystine transportert, or a genomic predisposition factor like a 
frequent polymorphism in one of the already known genes which - in combination with other predisposing elements (other genomic variants, life style) - causes the disease.

\section{Conclusion}

With the exclusion of $S L C 7 A 13 /$ AGT1 as the third cystinuria gene accounting for the SLC3A1 and SLC7A9 mutation negative cases, it becomes obvious that other genetic factors should be responsible for the cystinuria phenotype in nearly $15 \%$ of patients.

\section{Acknowledgements}

We thank A. Hesse, K. Hozyas, B. Golabek, and M. Slowik for providing us with patients DNA samples.

\section{Availability of data and materials}

are available on request.

\section{Authors' contributions}

KO performed the analyses and prepared the first draft of the paper. UV and SL provided patients, analysed the clinical parameter and contributed to the discussion of the paper. IK checked the molecular data and contributed to the discussion as well. TE initiated and supervised the study and edited the paper. All authors have read and approved the manuscript.

\section{Ethics approval and consent to participate}

All patients agreed in participation on the basis of a written informed consent template which also includes the use of data for publication. Genetic testing is approved by the ethical committee of the University Hospital Aachen (EK302-16).

The dataset(s) supporting the conclusions of this article is(are) included within the article.

\section{Consent for publication}

not applicable.

\section{Competing interests}

The authors declare that they have no competing interests.

\section{Publisher's Note}

Springer Nature remains neutral with regard to jurisdictional claims in published maps and institutional affiliations.

\section{Author details}

'Institute of Human Genetics, University Hospital, Technical University RWTH Aachen, Pauwelsstr. 30, D-52074 Aachen, Germany. ${ }^{2}$ Pediatric Hospital, University Hospital, University of Essen, Hufelandstr. 55, 45122 Essen, Germany. ${ }^{3}$ Department of Urology, St. Trudpert Hospital, Wilferdinger Str. 67, 75179 Pforzheim, Germany.

\section{Received: 29 November 2017 Accepted: 8 October 2018}

Published online: 20 October 2018

\section{References}

1. Chillarón J, Font-Llitjós M, Fort J, Zorzano A, Goldfarb DS, Nunes V, Palacín M. Pathophysiology and treatment of cystinuria. Nat Rev Nephrol. 2010;6(7): 424-34

2. Stapleton $F B, M c K a y ~ C P$, Noe HN. Urothiasis in children: the role of hypercalciuria. Pediatr Ann. 1987;16(12):980-92.

3. Pras E, Raben N, Golomb E, Arber N, Aksentijevich I, Schapiro JM, Harel D, Katz G, Liberman U, Pras M. Mutations in the SLC3A1 transporter gene in cystinuria. Am J Hum Genet. 1995;56:1297-303.

4. Calonge MJ, Gaparini P, Chillaron J, Chillon M, Gallucci M, Rousaud F, Zelante L, Testar X, Dallapiccola B, Di Silverio F, Barcelo P, Estivill X, Zorzano A, Nunes V, Palacin M. Cystinuria caused by mutations in rBAT, a gene involved in the transport of cystine. Nat Genet. 1994;6:420-5

5. Bisceglia L, Calonge MJ, Totaro A, Feliubadaló L, Melchionda S, García J, Testar X, Gallucci M, Ponzone A, Zelante L, Zorzano A, Estivill X, Gasparini P,
Nunes V, Palacín M. Localization, by linkage analysis, of the cystinuria type II gene to chromosome 19q13. 1 Am J Hum Genet. 1997;60:611-6.

6. Wartenfeld R, Golomb E, Katz G, Bale SJ, Goldman B, Pras M, Kastner DL, Pras E. Molecular analysis of cystinuria in Libyan Jews: exclusion of the SLC3A1 gene and mapping of a new locus on 19q. Am J Hum Genet. 1997;60:617-24.

7. Feliubadaló L, Font M, Purroy J, Rousaud F, Estivill X, Nunes V, Golomb E, Centola M, Aksentijevich I, Kreiss Y, Goldman B, Pras M, Kastner DL, Pras E, Gasparini P, Bisceglia L, Beccia E, Gallucci M, de Sanctis L, Ponzone A, Rizzoni GF, Zelante L, Bassi MT, George AL Jr, Manzoni M, De Grandi A, Riboni M, Endsley JK, Ballabio A, Borsani G, Reig N, Fernández E, Estévez R, Pineda M, Torrents D, Camps M, Lloberas J, Zorzano A, Palacín M. International Cystinuria consortium. Non-type I cystinuria caused by mutations in SLC7A9, encoding a subunit (Bo,+AT) of rBAT. Nat Genet. 1999;23:52-7.

8. Nagamori S, Wiriyasermkul P, Guarch ME, Okuyama H, Nakagomi S, Tadagaki K, Nishinaka Y, Bodoy S, Takafuji K, Okuda S, Kurokawa J, Ohgaki R, Nunes V, Palacín M, Kanai Y. Novel cystine transporter in renal proximal tubule identified as a missing partner of cystinuria-related plasma membrane protein rBAT/ SLC3A1. Proc Natl Acad Sci U S A. 2016;113(3):775-80.

9. Albers A, Lahme S, Wagner C, Kaiser P, Zerres K, Capasso G, Pica A, Palacin $M$, Lang F, Bichler KH, Eggermann T. Mutations in the SLC3A1 gene in cystinuric patients: frequencies and identification of a novel mutation. Genet Test. 1999:3(2):227-31.

10. Schmidt C, Albers A, Tomiuk J, Eggermann K, Wagner C, Capasso G, Lahme S, Hesse A, Lang F, Zerres K, Eggermann T. Analysis of the genes SLC7A9 and SLC3A1 in unclassified cystinurics: mutation detection rates and association between variants in SLC7A9 and the disease. Clin Nephrol. 2002:57(5):342-8.

11. Schmidt C, Vester U, Wagner CA, Lahme S, Hesse A, Hoyer P, Lang F, Zerres $K$, Eggermann T, al e. Significant contribution of genomic rearrangements in SLC3A1 and SLC7A9 to the etiology of cystinuria. Kidney Int. 2003;64(5): 1564-72.

12. Schmidt C, Vester U, Hesse A, Lahme S, Lang F, Zerres K, Eggermann T, al e. The population-specific distribution and frequencies of genomic variants in the SLC3A1 and SLC7A9 genes and their application in molecular genetic testing of cystinuria. Urol Res. 2004;32(2):75-8.

13. Brauers E, Hozyasz K, Golabek B, Slowik M, Schmidt C, Vester U, Zerres K, Eggermann T. Identification of novel cystinuria mutations in pediatric patients. J Ped Urol. 2006:2:575-8.

14. Brauers E, Vester U, Zerres K, Eggermann T. Search for mutations in SLC1A5 (19q13) in cystinuria patients. J Inherit Metab Dis. 2005;28(6):1169-71.

15. Botzenhart E, Vester U, Schmidt C, Hesse A, Halber M, Wagner C, Lang F, Hoyer P, Zerres K, Eggermann T, al e. Cystinuria in children: distribution and frequencies of mutations in the SLC3A1 and SLC7A9 genes. Kidney Int. 2002;62(4):1136-42

16. Sidi R, Levy-Nissenbaum E, Kreiss Y, Pras E. Clinical manifestations in Israeli cystinuria patients and molecular assessment of carrier rates in Libyan Jewish controls. Isr Med Assoc J. 2003:5(6):439-42.

17. Font-Llitjós $M$, Jiménez-Vidal $M$, Bisceglia $L$, Di Perna $M$, de Sanctis $L$, Rousaud F, Zelante L, Palacín M, Nunes V. New insights into cystinuria: 40 new mutations, genotype-phenotype correlation and digenic inheritance causing partial phenotype. J Med Genet. 2005:42(1):58-68.

18. Schmidt C, Vester U, Zerres K, Eggermann T. No evidence for a role of SLC7A10 in 19q13 in the etiology of cystinuria. Clin Nephrol. 2004;62(1):71-3.

19. Chatzikyriakidou A, Sofikitis N, Georgiou I. Identification of novel cystinuria mutations and polymorphisms in SLC3A1 and SLC7A9 genes: absence of SLC7A10 gene mutations in cystinuric patients. Genet Test. 2005;9(3):175-84.

20. Leclerc $D, W u Q$, Ellis JR, Goodyer P, Rozen R. Is the SLC7A10 gene on chromosome 19 a candidate locus for cystinuria? Mol Genet Metab. 2001;73(4):333-9.

21. Pineda M, Font M, Bassi MT, Manzoni M, Borsani G, Marigo V, Fernández E, Río RM, Purroy J, Zorzano A, Nunes V, Palacín M. The amino acid transporter asc-1 is not involved in cystinuria. Kidney Int. 2004;66(4):1453-64.

22. Eggermann T, Venghaus A, Zerres K. Cystinuria: an inborn cause of urolithiasis. Orphanet J Rare Dis. 2012;7:19 